\title{
Erratum to: A novel mathematical model of ATM/p53/NF-kB pathways points to the importance of the DDR switch-off mechanisms
}

Katarzyna Jonak ${ }^{1 \dagger}$, Monika Kurpas ${ }^{1 \dagger}$, Katarzyna Szoltysek ${ }^{2}$, Patryk Janus ${ }^{2}$, Agata Abramowicz $^{2}$ and Krzysztof Puszynski ${ }^{1 *}$

After publication of the original article [1], the authors noticed that there is an error with the Funding section. The correct Funding Section should be:

This work was financially supported by the Polish National Science Center (NCN) grants no. DEC-2012/ 05/D/ST7/02072 (KJ, MK, KP), N N518 287540 (KS, AA) and DEC-2012/05/B/NZ2/01618 (PJ).

\section{Author details}

${ }^{1}$ Faculty of Automatic Control, Electronics and Computer Science, Silesian University of Technology, Akademicka 16, 44-100 Gliwice, Poland. ${ }^{2}$ Maria Sklodowska-Curie Memorial Cancer Center and Institute of Oncology, Wybrzeze Armii Krajowej 15, 44-400 Gliwice, Poland.

Published online: 21 October 2016

\section{References}

1. Jonak J, et al. A novel mathematical model of ATM/p53/NF-KB pathways points to the importance of the DDR switch-off mechanisms. BMC Syst Biol. 2016;10:75. doi:10.1186/s12918-016-0293-0.

\footnotetext{
* Correspondence: krzysztof.puszynski@polsl.pl

${ }^{\dagger}$ Equal contributors

${ }^{1}$ Faculty of Automatic Control, Electronics and Computer Science, Silesian

University of Technology, Akademicka 16, 44-100 Gliwice, Poland

Full list of author information is available at the end of the article
} 